\title{
Towards a Social Contract for Genomics: Property and the Public in The 'Biotrust' Model
}

\author{
DAVID E. WINICKOFF \& LARISSA B. NEUMANN
}

\begin{abstract}
Large-scale genetics cohort studies that link genotypic and phenotypic information hold special promise for clinical medicine, but they demand long-term investment and enduring trust from human research participants. Currently, there are a handful of large-scale studies that aim to succeed where others have failed, seeking to generate significant private-sector investment while preserving long-term interest and trust of studied communities. With project planners looking for new modes of managing such complex collective endeavors, the idea of using a charitable trust structure for genomic biobanks has received increasing scholarly and policy attention. This article clarifies how thorny questions around property rights, the right to withdraw from research, access to materials, and funding might be handled within such a charitable trust structure to help produce a viable participatory framework for genomics.
\end{abstract}

\section{Introduction}

Large-scale genetics cohort studies that link genotypic and phenotypic information hold special promise for clinical medicine, but they demand long-term investment and enduring trust from human research participants. Recent experience in the United States, the UK, Iceland, Estonia, and Sweden suggests that population-level genomic studies pose particularly difficult legal and ethical challenges. ${ }^{1}$ Indeed, many population genomics projects with great scientific promise have failed due to unanticipated controversies over the distribution of property rights, data access, risk, and benefits across different project interest groups - such as researchers, human subjects, funders, medical institutions and private sector partners. ${ }^{2}$ Currently, there are a handful of large-scale studies that aim to succeed where others have failed, seeking to generate significant private-sector investment while preserving long-term interest and trust of studied communities.

With project planners looking for alternative governance models for genomic biobanks, the idea of using a charitable trust structure - as proposed in a $2003 \mathrm{New}$ England Journal of Medicine article by Winickoff and Winickoff ${ }^{3}-$ has received increasing scholarly and policy attention. ${ }^{4}$ This literature has highlighted the potential strengths of using charitable trust law to create an ideal institutional framework, but has also identified potential problems that may hinder its implementation. Addressing these questions directly, this article clarifies and develops this "Biotrust Model" with respect to key areas of implementation, including property rights, the right to withdraw from research, access to materials, and funding. The Biotrust Model and its treatment of property interests, as explicated in this article, remains a promising framework for community-driven governance in many genomic contexts. 


\section{Theoretical background: towards a new social contract for genetic biobanks}

As Winickoff and Winickoff have argued elsewhere, charitable trust law may be a useful legal and institutional tool for implementing a partnership relationship between biomedical researchers and research subjects in the genomic biobanking context. ${ }^{5}$ This idea was a response to a stream of empirical work suggesting how the existing regime of research governance has failed to manage large genomic programs. ${ }^{6}$ These programs have co-emerged with new scientific approaches, new technologies, and a new political economy of research, all of which have helped unsettle the existing regime of research governance in particular ways. These are worth reviewing.

First, as others have pointed out, DNA sequencing technology and bioinformatics have effectively transformed human tissue into a newly decipherable source of personal health information that uniquely identifies individuals. As a result, the tissue or blood sample has become equivalent, in privacy terms, to personal data in a medical record that can be digitized and shared across computer networks, and used to discriminate.

Second, it is a characteristic of DNA that sequences are shared across family and ethnic groups. This group turn carries important consequences for research ethics and institutional design. Sequence data derived from one person's sample can implicate close family members. ${ }^{7}$ Furthermore, research on a particular ethnic group or group of common geographical ancestry - such as those groups studied in the human haplotype projects - implicates all members of that group whether they participate directly in the research or not. ${ }^{8}$ This fact disrupts the pre-existing ethical paradigm of research subjects as distinct autonomous individuals, introducing important notions of group autonomy and solidarity that have emerged with force in recent population genomic projects. ${ }^{9}$

Third, and less noted, the creation of large genomic assemblages - often incorporating human tissue, medical information, and genealogical information -- for unforeseen research protocols has distanced genomics from the paradigm of research for which informed consent and IRB review was specifically tailored. In the past, research involving human subjects has been limited in time, and defined for a specific scientific study. Expanding the time-scale and openness of research use poses problems for achieving meaningful informed consent. ${ }^{10}$

Fourth, the new role of the private sector in these projects, and an increasing emphasis on property, has destabilized understandings between human research participants and academic researchers. Traditionally, this relationship involved the exchange of altruistic donation of time, bodily tissue, and medical information from human subjects in return for possible biomedical progress with general benefit. ${ }^{11}$ However, the growing role of private industry in biomedical research and discovery has introduced property, profit and distributional struggles into the equation. Furthermore, the commodification of biological information ${ }^{12}$ has raised new controversies around intellectual property, rights in samples, and scientific control. ${ }^{13}$

These trends make the design of an appropriate regulatory regime and institutional structure for genomic biobanks a novel challenge. Together they highlight how genomic research is not only a complex scientific endeavor, but also a complex social 
one. The off-the-rack regime of bioethics will no longer suffice, and instead we must rethink the processes and structures through which the affected communities and the public may deliberate upon, constitute, and enforce a new social contract for genomic research.

\section{The Biotrust Model: clarifying the legal and institutional structure}

The sustainability of large-cohort genomics will require institutional, procedural, and substantive legitimacy in order to secure ongoing funding, a progressive research program, and the willing participation of volunteer subjects over time. Using traditional informed consent and expert ethical review as a foundation, the Biotrust Model attempts to address these novel challenges by focusing new attention on issues of governance, constitutional powers, control of resources, and public benefit. The Biotrust Model aims to create a flexible institutional space through which the social contract around particular projects may be negotiated, ratified, and implemented. The hope is that the idea can be adapted and provide utility for new genomic projects as they emerge, especially projects attempting to implement innovative strategies for managing genomic resources for public benefit.

The Biotrust Model consists of a legal structure for handling the property rights and management of donated genetic and informational resources, and a social structure aimed at bolstering community participation, representation and trust in genomic governance - necessary conditions for sustainable collaborations. Because there has been some confusion and misstatement of how this model could operate, we believe it would be useful to clarify the model and respond directly to productive criticisms that have emerged regarding its operation.

The core idea of the Biotrust Model is to use the charitable trust as a legal framework to manage genomic resources and to govern genomic research more justly. ${ }^{14}$ A trust is a formal legal institution in which a property interest is held by one person or set of persons (the trustees) at the request of another (the settlor) for the benefit of a third party (the beneficiary). ${ }^{15}$ The property interest is conveyed to the trustee in a trust instrument that must clearly express the wish to create a trust. The settlor appoints a trustee of the property, who has legal fiduciary duties to keep or use the property for the beneficiary, creating a unique protective regime of trust law for safeguarding the interests of donors and other beneficiaries. ${ }^{16}$ The creation of a trust establishes a fiduciary relationship in which a trustee holds title to property, subject to an equitable obligation to keep or use the property for the benefit of the beneficiary. ${ }^{17}$

To be classified as a charitable trust, the purpose must be "charitable" and aim at the public good. ${ }^{18}$ Courts have defined "charitable" broadly in order to encourage "experiments to which it would be improper to devote the public funds or that the public would be unwilling to support until convinced by proof of their success." 19 Allocating benefits of the trust to specific groups rather than general public might be desired in certain biobanking situations because of the composition of the donor group, because of some heightened need of a particular segment of the public, or because research results may be relevant only to a small section of the public. Directing benefit to certain segments of the public would not jeopardize charitable status of a trust. In fact, at least in the Anglo-American tradition, the charitable classification of trusts requires that the purpose involve benefiting a class of persons and not simply the community at large. ${ }^{20}$ 
The charitable trust model combines a series of individual trust instruments, in which donors give certain property interests to the same trustee, the Biotrust Foundation, a non-profit organization that holds and manages the biorepository in accordance with the stated charitable purpose. The charitable trust structure would put a legally binding fiduciary obligation on the trustee to faithfully manage the resource according to the charitable purpose and the public benefit defined in the trust instrument. This fiduciary duty forbids trustees from self-dealing with the trust assets, engaging in conflict of interest transactions, and entering into transactions adverse to the trust. ${ }^{21}$ The Biotrust Foundation would be managed according to its by-laws, which the donors would also agree to, and which define the charitable purpose and the terms of public benefit. Procedural details could be changed according to the needs of the foundation's goals, by amending its by-laws.

The Biotrust Model adds important governance mechanisms to this basic charitable trust framework. In this model, the by-laws would specify that use of the trust property would be contingent on review and approval of two bodies, the Ethical Review Committee (ERC) and the Donor Advisory Committee (DAC). ${ }^{22}$ The ERC of the biorepository would provide peer review and ethical analysis of research protocols that call for access to biobank materials. This committee would be roughly equivalent to an Institutional Review Board (IRB), except that it would be more directly responsive to the collective interests of the donor group. Ideally, it would involve a significant number of donors so as to be more representative of the research subject population than current regulations require, at least in the United States. ${ }^{23}$

The Donor Advisory Committee would be a body composed of direct representatives of the donor group, and this group would help assure that the public value of the collected charitable donations would be maximized. This body would approve research protocols, but would also serve as a conduit between the donor group, the trustees, and the researchers in order to address controversial projects or issues as they arise. The DAC would provide an important democratic element to the governance of the trust, but is envisioned also as a flexible mechanism through which communication and learning could take place among the biobank constituents. In the United States, a similar body has emerged out of the Framingham Heart Study in Massachusetts, an ongoing study of fifty years in which the subject group has taken an interest and role in project decision-making. ${ }^{24}$ These representative could be elected periodically through proxy voting, in a process akin to the election of board members by shareholders of a corporation. 


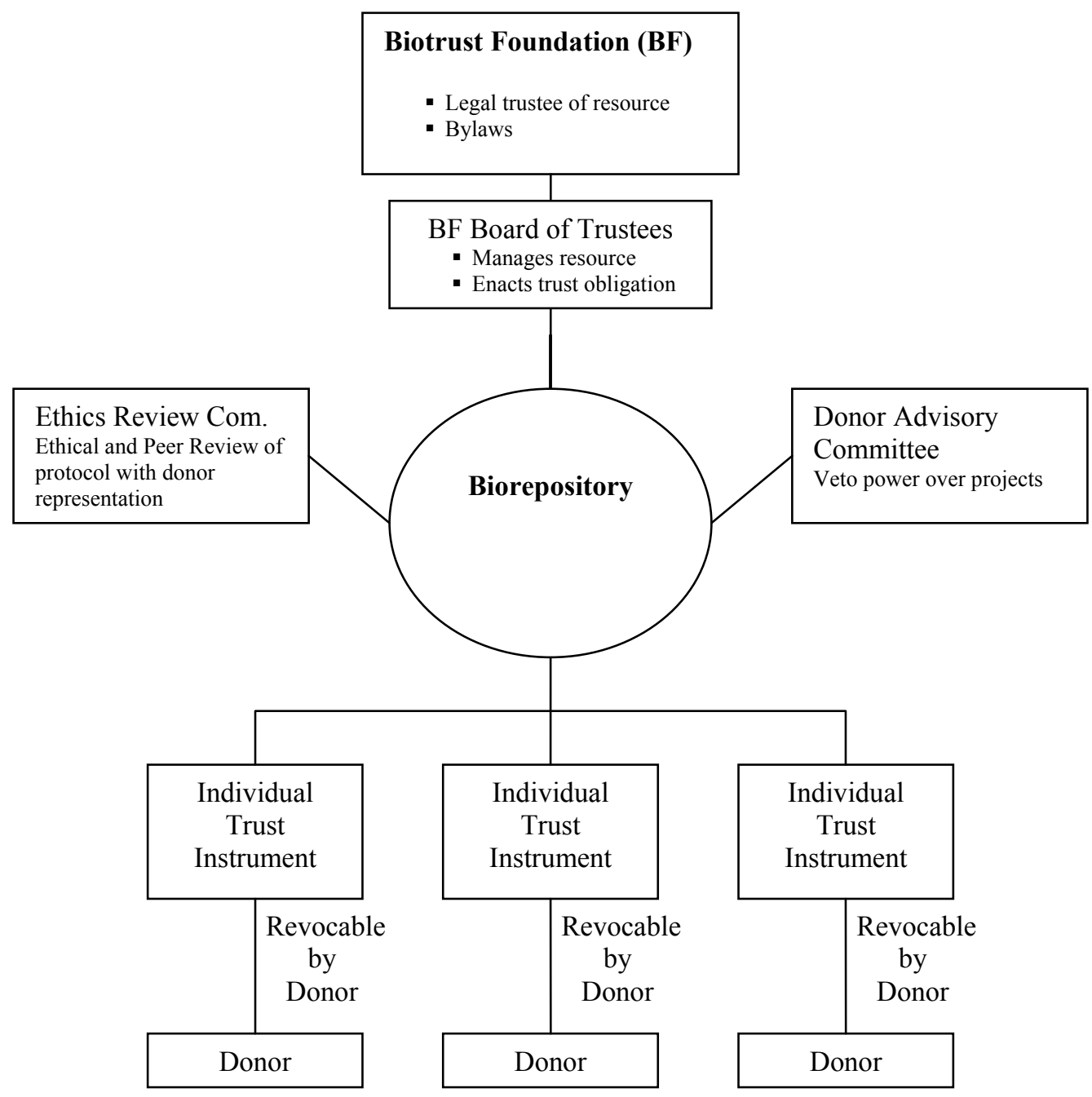

\section{Response to criticisms}

Critics in Europe and the UK have highlighted certain advantages of this model. First, it respects the altruistic intent of donors, while ensuring that their goodwill is not exploited. Second, it imposes a duty on the resource managers to make the resource productive. Third, fiduciary law addresses a power imbalance between the settlor/beneficiaries and the trustee, in contrast to the consent model, which has often been criticized for failing to take into account the power imbalance between doctor and patient. ${ }^{25}$ Fourth, the separation of storage and usage reduces the conflicts of interest in making prioritization decisions about the resource, enhances the opportunity for ethical review, and encourages interest groups to participate in decision-making. ${ }^{26}$ Fifth, the procedural mechanisms and structures are likely to help mediate among diverse interests implicated by the research. Other advantages in terms of transparency, donor representation, autonomy, and scientific utility are discussed in the original article, and need not be rehearsed here. ${ }^{27}$ 
Recent scholarship has also raised important concerns with the legal architecture of the charitable trust model. This criticism, especially that of Boggio, ${ }^{28}$ has been helpful as an analytical spur towards better specifying and clarifying how the model could be useful. Here we discuss the significant issues for genomic governance raised by Boggio and others, and explain how the charitable trust model could be designed to resolve them.

\section{A. Property rights of biological samples}

One concern Boggio raises is that the charitable trust idea fails to answer important questions concerning ownership of tissue samples, derived data, and the database itself. Boggio notes that "property in the body" is ethically controversial and legally inadmissible in certain jurisdictions, and this might make the model incompatible with many legal systems to the extent that it requires a formal recognition of property in the body. The question of ownership of samples is a thorny one, and it is important to clarify why establishing the charitable trust would violate neither the spirit nor the letter of this prohibition.

As a threshold issue, it should be pointed out that the charitable trust model does not require the formal recognition of "property in the body," at least not as that phrase is normally understood. The rejection of "property in the body" in certain jurisdictions limits the free alienability of bodily entities integral to personhood, and is based on the visceral and ethical disdain for commodification of the human body. ${ }^{29}$ However, recognizing the existence of property-like interests in human tissue is not tantamount to endorsing a full spectrum of alienable property rights, for example the right to sell tissue at any time for cash compensation. As one commentator has put it,

... the equation of any property right with the full spectrum results in the erroneous impression that recognizing the existence of property rights in human tissue is tantamount to endorsing a right to sell any body party, at any time, for cash compensation ... . A richer and more complete understanding of property rights, however, emphasizes the tremendous variety of possible property regimes in human biological materials. Property is a flexible concept, not an all-or-nothing one. ${ }^{30}$

The creation of a charitable trust would not require a general property right in the body, but something much narrower: the recognition that personal rights of control, and use, and access in pieces that can be extracted without harm (indisputably held by the person prior to donation) may form the basis of a legal trust. ${ }^{31}$

In fact, the charitable trust is a legal tool for effecting this norm of noncommodification. The structure relies on the recognition of a property-like interest in donated materials only for the narrow purposes of creating an enforceable trust relationship, one that embeds control of tissue in a managed network of noncommodity exchange: samples must be used according to the terms of the trust, and the trustee enforces this use. Furthermore, the donor retains some control over the use of the donation because she can withdraw according to the trust agreement. Using a revocable trust relationship actually ensures that donors retain an equitable interest in their donation, suggesting a sort of joint control with the trust (see below). ${ }^{32}$ This joint control of the donation does not defeat the ability to create a trust. Here the land 
analogy helps: a person can give a mortgaged property to be held in trust even though they do not own a complete inalienable right to that property.

Within some jurisdictions, such as the United States, body parts are already understood as subject to "property interests" or "quasi-property" in certain contexts, especially where the bodily materials are not integral to the person's health and functioning. ${ }^{33}$ The idea of a limited or quasi-property right actually comports with the WHO Regional Office report that Boggio cites, recommending that participants in biomedical research should have the "primary control [of] samples or the information generates from them," and that their legal interest "is akin to a property right." 34 In these jurisdictions, all that is required to create a trust is that donors transfer these rights to the charitable trust.

Boggio is also concerned that the charitable trust model is in conflict with policies that provide that the donation of the tissue sample does not transfer property in the sample to the recipient, noting that the "Icelandic Acts on Biobanks explicitly provides that the biobanker is not to be considered the owner of the biological sample." ${ }^{35}$ We would like to draw a distinction between ownership, which suggests the full and undivided bundle of rights associated with property, and possessing certain property interests. As Harvard property scholar Joseph Singer puts it, "the core image of ownership is ownership of a home. The core conception is the notion of absolute control; ownership is the ability to do what you like with your own, without having to account to anyone else for your actions." ${ }^{, 36}$ If ownership implies absolute control and complete freedom to use, access, sell without account to others, than the trustees can't be said to "own" the samples under the charitable trust model. We imagine a so-called "donor-advised trust," in which the materials are actually comanaged by donors, trustees, and the sitting ethics board in accordance to the charitable intent of the donors. In this sense, the trustee actively holds many of the traditional "sticks" in the bundle of rights associated with property except the right to sell freely. These include rights granting access, use, and control, but only for certain limited purposes set out in the trust purpose and by-laws. Furthermore, the donors retain the ability to enforce those limitations through participatory governance and the right to revoke the gift. ${ }^{37}$ Thus, this system is specifically designed to address the ethical, legal and social problems associated with the free alienation of bodily materials: instead of allowing donated materials to disappear into the unaccountable vortex of "research" or the market exchange, the charitable trust actually institutionalizes the connection between body part and person.

In practice, to use the "no property in the body" idea to deny research donors the ability to put these materials in a charitable trust would achieve the perverse result of facilitating their commodification. Whether the law recognizes this fact or not, biological samples have become commodified in the political economy of genetics research. $^{38}$ The Biotrust Model proposes a way to govern and regulate the exchange of bodily material in order to mitigate some of the concerns that are presented in either a system of complete ownership or complete lack of ownership. Indeed, this institutional model is specifically designed to render the exchange of human research materials more accountable to the donors and more consistent with their charitable intent. 


\section{B. Property rights in derived data and databases}

Dealing with derived data and databasing from a property perspective are less difficult to address. If the charitable trust institution itself performs research and in the process derives data from peoples' donations, then that data is clearly controlled by the trust itself, and would then have to be managed by the trustee according to the charitable purpose and by laws of the trust. The database itself, if constructed by the Biotrust Foundation, will also be owned and controlled by the trust itself. This accords with the typical treatment of data and research tools created through research.

Of course, commercial entities that use donated research material to conduct research have a legitimate interest in the fruit of their labor. ${ }^{39}$ If the trustees decide to grant outside researchers or companies access to particular data or samples, and those research entities construct their own electronic database, ownership of this database would be negotiated in the licensing agreement between the trust and those researchers. However, based on the charitable trust model the researchers would never have complete ownership of the research material. For example, the research material could not be used for some alternative research that is different from the original research protocol approved by the trust's Ethical Review Committee and the Donor Advisory Committee. The flexible nature of the model allows the Biotrust Foundation's bylaws to determine the interest that commercial entities have over the research material. Therefore, the procedural details about the right for commercial entities to access and use research material will vary depending on the charitable goals and by-laws of the Biotrust Foundation.

\section{Managing access to samples and information}

As the previous sections suggest, the Biotrust Model assigns the role of managing access to the board of trustees, although in our Biotrust Model they are constrained by the Ethical Review Committee (ERC), Donor Advisory Committee (DAC) and donor rights of withdrawal (described below). This much has been discussed briefly elsewhere. ${ }^{40}$ Boggio correctly points out, however, that our structure does not specify how access to samples and sensitive data will be managed by the trustees. He raises a series of questions that will help us clarify how a charitable biotrust might be implemented.

First, Boggio notes that the charitable trust structure does not answer whether and how external research groups will access samples, data derived from them, and/or sensitive health information collected along with samples. It is true that a charitable trust structure by itself does not provide an answer. But this fact provides flexibility that is actually a strength of the legal structure. ${ }^{41}$ It will be up to the project organizers, donor group, and board of trustees to develop acceptable by-laws for the trust that may dictate guidelines for the degree of access. We would suggest that these be negotiated before the architecture is set up, perhaps through a process of public consultation, ${ }^{42}$ but the by-laws could be written to permit later refinement in the interest of pragmatism. These by-laws, negotiated before hand and refined later, should also address any principles of prioritization as between commercial and academic protocols, another open issue Boggio has raised. 
If past experience is any judge, researchers in both the commercial and non-profit sectors will likely ask for access to biological samples, DNA sequence information, and any data that the charitable trust might hold. However, recall that under our biotrust model, the protocol and any commercial deals would have to be approved not only by the trustees, but also by the ERC and the DAC. Furthermore, access would be limited by any statutory or regulatory requirements. Privacy rules and human research protections in many countries will likely prevent the transfer of identifiers along with samples and health information, at least without individual authorization. ${ }^{43}$

Finally, Boggio asks whether participants would be informed if research findings might affect their individual care. This is an important issue, but one that can be dealt with through the individual donor agreements with the trust. In the interest of enhancing the autonomy of individual donors, and potential direct benefits of the research, we would agree with previous commentators that donors be able to indicate on the consent form - by checking a box - if they would like to be recontacted (so long as identifiers still allow it) in therapeutic situation. ${ }^{44}$ Recontact could be pursued through the donor's primary care physician.

Boggio states that "in the end, the trustees will be asked to make these sorts of judgments in adopting the policies that regulate third-party access. Most of the answers will only lie in those rules governing the biobank and its contractual relations with external actors rather than in the governance framework." ${ }^{, 45}$ While this could be true if the trust instrument gives trustees control, the choices of managers can be constrained and regulated in a number of ways. Additionally, we have suggested a set of policies to help guide the thinking of project planners as they consider how they might accomplish different access goals through the by-laws of the trust.

\section{Implementing the right of withdrawal}

As we have discussed elsewhere, a charitable trust in the biorepository context must make special accommodation for research participants, allowing them to be able to withdraw their samples from the biobank at any time. ${ }^{46}$ Boggio raises the question of whether a revocable charitable trust is able to effectuate this right of withdrawal.

First, the right to withdraw one's samples from the charitable biorepository needs to be distinguished from the opt-out window, another mechanism previously described through which the so-called "open consent" problem is mitigated. For efficiency reasons, most biobanks seek an open permission from donors at a single point in time for future research projects instead of recontacting and reconsenting donors when new protocols arrive. These so-called "open consents" pose problems for traditional notions of informed consent, which require that the research participant understand the risks and benefits of particular research protocols. Stanford University bioethicist Henry T. Greely and others have argued persuasively that biobanks' requests for general permission should be allowed only if additional safeguards are in place. ${ }^{47}$

The "opt-out window" is a mechanism that increases the autonomy of research subjects who give open permission, for it allows the donors to review particular protocols and gives them a time-limited window in which to opt-out of that particular protocol. This mechanism honors the traditional norm of granting research subjects the right to withdraw from particular research project, while not overburdening the 
biobank with recontact and reconsent. Through electronic newsletters, normal mail, and a web site, the biotrust foundation would convey information to donors, allowing donors to make informed decisions about withdrawing from specific research projects for a short period of time before the research begins.

Second, the revocable charitable trust is indeed a mechanism that could effectuate the right to withdraw one's sample from the biobank at will or in cases of non-adherence of trustees to the charitable purpose. A revocable trust is a trust that allows the settlor to revoke the trust property, according to the terms of the trust instrument. Boggio states that "technically it is not a 'revocable' trust because in this case, the withdrawal of biological material of a single settler/donor does not revoke the whole trust." incorrect as a matter of law that the creation of a revocable trust relationship between individual donors and a single trustee would require that if one donor withdraws, the entire biobank be revoked. For instance, if one made a conditional donation of land to a charitable trust, say the National Land Trust, and the conditions were not met, the property would revert to the donor without interfering with trust's other obligations. While legal partnerships might embody this "all-for-one-one-for-all" idea, revocable trusts do not. The key conceptual point is that people donate into the existing trust, but under certain conditions, such that the Biotrust Foundation has individual revocable trust relationships with each donor.

Individual revocable trust relationships are ideal for implementing the Biotrust Model that we advocate for biobanks. In a revocable trust the settlor maintains equitable rights in the trust property, though the trustee holds legal title. If a trust is not revocable the settlor usually has no equitable claim to enforce the terms of the trust or to terminate the trust. ${ }^{49}$ Most jurisdictions assume that a trust is revocable unless the trust instrument indicates otherwise.

Another concern Boggio raises is the status of the donated material at the individual donor's death. One simple solution is for charitable biotrusts to allow for individual variations in the trust instruments that indicate the settlor's desire upon death. For example, settlors could indicate that they want the donation destroyed at their death or they could indicate that they want the sample permanently donated without any restriction.

The trust bylaws and individual trust instruments would set the policy for withdrawal. As Boggio states, withdrawal might entail a number of actions, such as returning samples to the participants, destroying samples, anonymization, removing identifying information, destroying genetic data derived from the sample or simply no longer use them. There are some concerns about allowing donors to withdraw from scientific research at any point because scientist may not want to invest in research that could possibly be terminated or damaged by a withdrawal. Pragmatism requires that once a research project is started, the donor would not have the ability to withdraw from that specific study. But at any time the donor could completely withdrawal their material from any future research.

Creating a revocable trust ensures that donors maintain the legal rights necessary to withdraw their donation and enforce the duties of the trustees. In this way, the revocable status of donations helps advance the representation, deliberation, and 
accountability of researchers to the donors, which is appropriate in research using biological material and information.

\section{E. Funding}

As stated in previous work, initial funding for a Biotrust should be committed in the public interest by state or charitable donors, and experience indicates that state governments, medical charities, and even particular disease groups may be willing seed such an entity. ${ }^{50}$ The key benefit of the charitable trust is that the collection must be managed for public benefit. However, some relationship with the private sector may be desirable to promote research and to funnel money back to support the trust infrastructure. Once the charitable biotrust foundation is started it will likely sustain itself by charging reasonable fees for access to cover operation expenses.

Furthermore, depending on the goals of the charitable trust, the biotrust foundation could contract for intellectual property rights in the research.

Boggio has stated that the Winickoff \& Winickoff model insufficiently details how it could balance openness and public-benefit with commercial collaboration. ${ }^{51}$ Boggio is correct that the Biotrust idea by itself says little about how an appropriate balance should be struck between maintaining open access and encouraging private collaboration. The optimal balance cannot be prescribed, but will have to be worked out in practice. The fact is, there are various ways that charitable biotrusts could strike this balance, depending on the goals and purposes of biotrust and its donors.

Managing the public-private interface in genomics in a way that is acceptable to those involved may be one of the greatest challenges facing these endeavors. A key strength of the Biotrust Model lies in its governance architecture -- in which power is shared across the board of trustees, donor representatives, and the ethics committee. In its ideal form, this architecture would help foster a Habermasian space ${ }^{52}$ for public deliberation and learning not only about the use and operation of the biobank, but also about the new genetics and its effect on the political economy of health. Joint governance creates the potential ability to deliberate policies regarding the private sector. We imagine that the donor representatives will be in contact with the donor community through newsletters, public hearings and comment periods. These efforts may be useful to achieve pragmatic policies, so long as they are ratified by the community.

\section{Conclusion}

Biomedical research has shifted meanings with the advent of new genetic technologies and an expanded role for the private sector. Large genomic assemblages embody these changes, but they retain a strong public character and mandate due to the collective demands of this type of research. The ongoing project to construct a genomic governance that acceptably orders the interface between public and private will likely fail until we reconceive genomics as an enterprise driven not by profit, but by collective political will. The Biotrust Model attempts to create a framework for this reconception. It is an attempt to create a vigorous public space through which a new social contract for biomedical research may be negotiated and ratified. At the same time, it seeks the elusive balance between respecting the dignity of human persons and generating public value, a balance that has been unsettled by the new 
modalities of biological science, technology, and property. In order to accomplish these tasks, it constructs a hybrid legal identity for genomic resources, one that stakes out a position between personhood and property, gift and commodity, group and individual, public and private. Its merit, if it has any, will be measured not by its theoretical novelty, but by its practical ability to open pathways of democratic governance through complex technoscientific endeavors.

\section{Acknowledgements}

The authors wish to thank Marjorie Shultz, Eric Rakowski, and Heather Butterfield for helpful input on this article.

${ }^{1}$ See, e.g., G. Williams, Bioethics and Large-scale Biobanking: Individualistic Ethics and Collective Projects. Genomics, Society and Policy 2005; 1,2: 50-66; D. Winickoff, Governing Population Genomics: Law, Bioethics, and Biopolitics in Three Case Studies. Jurimetrics 2003; 43: 206.

2 See, e.g., K. Philipkoski, Framingham Gene Project Killed. Wired 2001 (Jan. 2); H. Rose, An Ethical Dilemma: The Rise and Fall of UmanGenomics - the Model Biotech Company? Nature 2004; 425: 123-124; A. Abbott. Icelandic Databases Shelved as Court Judges Privacy in Peril. Nature 2004; 429: 118; J. Burgermeister. Estonia genome project lives on. The Scientist 2004 (28 April).

3 D. Winickoff and R. Winickoff, The Charitable Trust as a Model for Genomic Biobanks. New England Journal of Medicine 2003; 349: 1180-1184.

4 J. Bovenberg, Whose Tissue is it Anyway? Nature Biotechnology 2005; 23: 929-933; A. Boggio, Charitable Trust and Human Genetic Databases: The Way Forward? Genomics, Society and Policy 2005; 1: 41-49; PropEur Workshop on Property in the Human Genome, "Benefit-sharing and the Charitable Trust as Models of Regulation in Intellectual Property Rights" (8-9th July 2004, Cardiff University, UK). http://www.propeur.bham.ac.uk/Cardiff\%20workshop.htm; In the United States, the author (DW) has been working with the U.S. Veterans Administration and the University of Utah to apply aspects of the Charitable Trust Model for governing genomic biobanking projects.

${ }^{5}$ Winickoff \& Winickoff, op. cit. note 3.

${ }^{6}$ For instance, Reardon has shown how in the Human Genome Diversity Project the project planners failed to find an acceptable solution to the problem of obtaining group consent among the indigenous communities to be sampled. J. Reardon, The Human Genome Diversity Project: A Case Study in Coproduction. Social Studies of Science 2001; 31: 357-8. Also, the Framingham Heart Study population fell apart due to disagreements between private funders, university sponsors, and government agencies over data sharing and intellectual property. See Philipkoski, op. cit. note 2.

This fact has, among other things, recently changed the policy discourse on DNA databanks for forensic purposes which, because of familial searching, effectively expands these databases exponentially. F. Bieber, C. Brenner, and D. Lazer, "Data mining the family tree: identification of relatives using genetic kinship analysis of DNA databases." Conference presentation at the National Conference for Digital Government Research, Atlanta, 2005.

${ }^{8}$ G.J. Annas, Rules for Research on Human Genetic Variation - Lessons from Iceland. New England Journal of Medicine 2000; 342: 1830-1833.

9 B. Knoppers and R. Chadwick, Human Genetic Research: Emerging Trends in Ethics. Nature Reviews: Genetics 2005; 6: 75-79. H.T. Greely, The Control of Genetic Research: Involving the "Groups Between." Houston Law Rev 1997; 33: 1397-430; Reardon, op. cit. note 6.

10 National Bioethics Advisory Commission (U.S.). Research Involving Human Biological Materials: Ethical Issues and Policy Guidance (1999); 59-61.

${ }^{11}$ See, e.g., Richard Titmuss. 1997. The Gift Relationship: From Human Blood to Social Policy. $2^{\text {nd }}$ ed. A. Oakley and J. Ashton, eds. New Press.

12 Rose, op. cit. note 2.

13 See, e.g., K. Sunder Rajan, Genomic Capital: Public Cultures and Market Logics of Corporate Biotechnology. Science as Culture 2003; 12,1: 87-121.

${ }^{14}$ Winickoff \& Winickoff, op. cit. note 3. 
${ }^{15}$ Black's Law Dictionary, $7^{\text {th }}$ Edition.

${ }^{16}$ For a more in depth look at trust law as a protective regime for safeguarding the interest of investors see J. Langbein, The Secret Life of the Trust: The Trust as an Instrument of Commerce. Yale Law Journal 1997; 107: 182.

${ }^{17}$ Most basically, charitable trust status imposes fiduciary duties on holder of property - in this case, the charity-recipient of the donor's gift. See generally Restatement (Third) of Trusts. 2003. § 5 (distinguishing trust relationship from contracts, conditions, and other arrangements).

${ }^{18}$ G.G. Bogert, G.T. Bogert. 1992. The Law of Trusts and Trustees. $2^{\text {nd }}$ ed. 323-9.

${ }^{19}$ A.W. Scott. 1989. Trusts. 4rth Ed. $\$ 375$.

${ }^{20}$ Id. at $\$ 374.7$. Thanks to one of our anonymous reviewers, who astutely helped us identify, clarify, and sharpen this issue.

${ }^{21}$ J. Langbein, The Contractarian Basis of the Law of Trusts, Yale Law Journal 1995; 105: 655.

22 This would effectively impart veto power over particular projects to both committees, which are envisioned to operate through majority voting.

${ }^{23}$ In the U.S., the so-called "Common Rule" that protects human research subjects in federally funded research requires only that "each IRB shall include at least one member who is not otherwise affiliated with the institution and who is not part of the immediate family of a person who is affiliated with the institution.” 45 C.F.R. $\$ 46.107$ (d), IRB membership. We would recommend that the number of community members or research participants on the biobank's ethical review committee amount to half, or nearly half, of the body.

${ }^{24}$ Personal communication with D. Levy, Director of the Framingham Heart Study. See also D. Levy and S. Brink. 2005. A Change of Heart: How the People of Framingham, Massachusetts, Helped Unravel the Mysteries of Cardiovascular Disease. Knopf.

${ }^{25}$ Remarks by D. Dickenson, PropEur Workshop on Property in the Human Genome, Benefit-sharing and the Charitable Trust as Models of Regulation in Intellectual Property Rights (8-9th July 2004, Cardiff University, UK). http://www.propeur.bham.ac.uk/Cardiff\%20workshop.htm

${ }^{26}$ Boggio, op. cit. note 4.

${ }^{27}$ Winickoff \& Winickoff, op. cit. note 3.

${ }^{28}$ Boggio, op. cit. note 4 .

${ }^{29}$ The moral fabric of western society is deeply woven with strains of thought condemning the characterization of the human body and its derivatives as property that can be sold freely on the market. For further discussion see M.J. Radin, Market-Inalienability. Harvard Law Review 1987; 100: 1849.

30 J.D. Mahoney, The Market For Human Tissue, Virginia Law Review 2000; 86: 163.

${ }^{31}$ At least in the Anglo-American legal tradition, property is actually treated as a "bundle of sticks," a package of rights possessed by persons relative to particular objects, including: the right to possess one's property, the right to use it, the right to exclude others, the right to transfer ownership by gift or sale, the rights to dispose of one's property after death, and the right not to have one's property expropriated by the government without payment of compensation. The legal concept of property permits fragmentation: the bundle of sticks may be separated and transferred even if the owner does not hold all of the sticks in the bundle. See, e.g., B.A. Ackerman. 1978. Private Property and the Constitution. Yale University Press, (distinguishing between the lay man's idea of property as an object and arguing that property should not be understood as a thing but as a "set of legal relations between persons governing the use of things"). See also, R. Rao, Property, Privacy, and the Human Body. Boston University Law Review 2000; 80: 359.

${ }^{32}$ Cf. UK Biobank, where UK Biobank will be the legal owner of the database and the sample collection, where "participants will not have property rights in the samples," but in which "UK Biobank will serve as the 'steward' of the resource, maintaining and building it for the public good." See UK Biobank, Frequently Asked Questions, at <http://www.ukbiobank.ac.uk/about/ faqs.php\#anonymous $>$. It is unclear whether under the UK Biobank policies, donors will retain any equitable interest in their samples, which may make withdrawal of samples contingent on consent of UK Biobank. Under the Biotrust Model, the right to withdraw samples would be a retained by the donor, as explained in more detail below.

${ }^{33}$ In American law, bodies and body parts are treated under regimes of both privacy and property, depending on the bodily material at issue and the social context. Pieces of the body like organs that are 
more important for core bodily functioning, tend to be less alienable than pieces that can be detached without harm or serious consequence, such as sperm, blood, eggs, hair, etc. See Rao, op. cit. note 32. The types of materials needed to create genomic biobanks are more like the latter type of materials, for they consist mostly of blood and surgical biopsies.

${ }^{34}$ Boggio, op. cit. note 4, p. 46.

${ }^{35}$ Id.

36 J.W. Singer. 2000. Entitlement: The Paradoxes of Property. Yale University Press: 29.

${ }^{37}$ In this sense, the donated property interest is also akin to a voluntarily donated easement on a piece of land, an easement being "an interest in land owned by another person, consisting in the right to use or control the land ... for a specific limited purpose." Black's Law Dictionary, $7^{\text {th }}$ Edition.

38 J.D. Mahoney, The Market For Human Tissue, Virginia Law Review 2000; 86: 163.

39 At least under a labor theory of value found in Locke and others.

${ }^{40}$ Winickoff \& Winickoff, op. cit. note 3.

41 F.W. Maitland. 1936. Equity, p. 23 (stating that the trust "is an 'institute' of great elasticity and generality; as elastic, as general a contract."

42 Such a process of public consultation has precedent in previous public encounters with biotechnology. See, e.g., GM Nation, the UK's attempt to create a series of public consultations on genetically modified organisms. $<\underline{\mathrm{http}} / / / \mathrm{www}$. gmnation.org.uk/ $>$. See also admirable efforts underway as part of UK Biobank, <http://www.wellcome.ac.uk/doc WTD003284.html>. It remains to be seen, however, how successful these particular public consultation initiatives have been or will be.

${ }^{43}$ E.g., in the United States, the recently enacted HIPAA Privacy Rule, 45 C.F.R. $\$ 164.501-508$.

${ }^{4}$ This is the procedure used in many existing population studies, e.g., genetics research involving the Utah Population Database. See J.E. Wylie, G.P. Mineau, Biomedical databases: protecting privacy and promoting research. Trends in Biotechnology 2003; 21,3:113-6.

${ }^{45}$ Boggio, op. cit. note 4, p. 46.

${ }^{46}$ Winickoff and Winickoff, op. cit. note 3.

47 Greely would allow signed "permission" for unforeseen research with provisions stipulating the conditions of recontact, an absolute right of withdrawal at any time, time limits, limitations on availability of information to third parties, group permission requirements on top of individual permission, disclosure of commercial interests, confidentiality stipulations, and community benefits. H.T. Greely, Breaking the Stalemate: A Prospective Regulatory Framework for Unforeseen Research Uses of Human Tissue Samples and Health Information. Wake Forest Law Review 1999; 34:752-58 48 Boggio, op. cit. note 4, p. 46.

${ }^{49}$ Some courts in the U.S. have recently allowed settlors to enforce the trust instrument even if the trust is not revocable. In many cases the settlor does not have standing to sue a charity for the violation of the terms of the charitable gift. See Carl J. Herzog Foundation, Inc. v. University of Bridgeport and G. Manne, Agency Costs and the Oversight of Charitable Organizations. Wisconsin Law Review 1999; 1999: 241-242.

${ }^{50}$ Some disease advocacy groups have founded their own biobanks to attract researchers to study their disease. See D. Winickoff, op. cit. note 1.

${ }^{51}$ Boggio, op. cit. note 4, p. 48.

52 This term refers to Jürgen Habermas' idealized notion of a "public sphere" - a crucial political space between the state and private spheres -- in which individuals can collectively engage in deliberation, communication, identity formation, and the negotiation of norms. See, e.g., J. Habermas. 1996. Between Facts and Norms: A Discourse Theory of Law and Democracy. William Rehg, trans.. MIT Press: 298-361. 